\title{
Assessment of Prevalence of Abnormal Neurological Findings on MRI in Patients Presenting with Chronic Headache: A Clinical Study
}

\author{
Pradeep Shankarrao Patil ${ }^{1}$, Niranjan Bapu saheb Patil ${ }^{1}$ \\ ${ }^{1}$ Professor, Department of Radiodiagnosis, D.Y.Patil Medical College, Kolhapur.
}

\section{Abstract}

Background: Chronic headache is one of the common presenting complaints in patients reporting to general practitioner. Magnetic resonance imaging (MRI) is a medical imaging technique used to aid diagnosis but unlike CT it does not use ionizing radiation. Hence; we assessed the prevalence of abnormal neurological findings on MRI in patients presenting with chronic headache. Subjects and Methods: A total of 100 patients reporting to the department with chief complaint of non-specific chronic headache were enrolled in the present study. Detailed demographic data and past medical history of all the patients was obtained. We also obtained complete history of present illness. MRI was done in all the patients under the hands of skilled and experienced radiologists. MRI findings were analyzed and were summarized in Microsoft excel sheet and were assessed by SPSS software. Chi- square test was used for assessment of level of significance. Results: Mean age of the patients of the present study was 40.8 years. Majority of the patients ( 49 percent) belonged to the age group of 30 to 50 years. 31 percent of the patients belonged to the age group of less than 30 years. 58 percent of the patients of the present study were males while the remaining 42 percent were females. Abnormal MRI findings were found to be present in 22 percent of the patient population. Conclusion: Chronic headache is a common problem affecting significant proportion of patient populating. Significant proportion of patients with chronic headache has associated abnormal MRI findings.

Keywords: Chronic, Headache, MRI.

Corresponding Author: Dr. Niranjan Bapu saheb Patil, Professor, Department of Radiodiagnosis, D.Y.Patil Medical College, Kolhapur.

Received: June 2019

Accepted:June 2019

\section{Introduction}

\section{Subjects and Methods}

Chronic headache is one of the common presenting complaints in patients attending the out patient's department or emergency care of any hospital or general practitioner however, only about $10 \%$ of patients with recurrent headache have secondary cause. Headache is considered primary when a disease or other medical condition does not cause the headache. Primary headaches are benign, chronic and not life threatening. ${ }^{[1-3]}$

Patients with pre-existing primary headaches with exacerbations, needs further investigations to rule out life threatening secondary headaches. This may have caused a new type of secondary headache. Magnetic resonance imaging (MRI) is a medical imaging technique used to aid diagnosis but unlike CT it does not use ionizing radiation. Instead, it uses a strong magnetic field to image a person's anatomy. Compared to CT, MRI can provide increased contrast between the soft tissues of the body. ${ }^{[4-6]}$ Hence; the present study was planned for assessing prevalence of abnormal neurological findings on MRI in patients presenting with chronic headache.
The present study was planned in the department of radiodiagnosis of the medical institute and it included assessment of prevalence of abnormal neurological findings on MRI in patients presenting with chronic headache. Ethical approval was obtained from the ethical committee of the institution. Written consent was obtained after explaining in detail the entire research protocol. A total of 100 patients reporting to the department with chief complaint of non-specific chronic headache were enrolled in the present study. Detailed demographic data and past medical history of all the patients was obtained. We also obtained complete history of present illness. MRI was done in all the patients under the hands of skilled and experienced radiologists. MRI findings were analyzed and were summarized in Microsoft excel sheet and were assessed by SPSS software. Chi- square test was used for assessment of level of significance.

\section{Results}

In the present study, a total of 100 patients with chronic headache were analyzed. Mean age of the patients of the present study was 40.8 years. Majority of the patients (49 percent) belonged to the age group of 30 to 50 years. 31 percent of the patients belonged to the age group of less 
than 30 years. 58 percent of the patients of the present study were males while the remaining 42 percent were females. Abnormal MRI findings were found to be present in 22 percent of the patient population.

\begin{tabular}{l}
\hline Table 1: Age-wise and gender-wise distribution \\
\begin{tabular}{|l|l|l|l|l|}
\hline Parameter & $\begin{array}{l}\text { Number of } \\
\text { patients }\end{array}$ & $\begin{array}{l}\text { Percentage } \\
\text { of patients }\end{array}$ & $\begin{array}{l}\text { p- } \\
\text { value }\end{array}$ \\
\hline \multirow{2}{*}{$\begin{array}{l}\text { Age } \\
\text { group } \\
\text { (years) }\end{array}$} & Less than 30 & 31 & 31 & \multirow{2}{*}{0.77} \\
\cline { 2 - 4 } & 30 to 50 & 49 & 49 & \\
\cline { 2 - 4 } & $\begin{array}{l}\text { More than } \\
50\end{array}$ & 20 & 20 & \\
\hline \multirow{2}{*}{ Gender } & Males & 58 & 58 & \\
\cline { 2 - 4 } & Females & 42 & 42 & \\
\hline
\end{tabular}
\end{tabular}

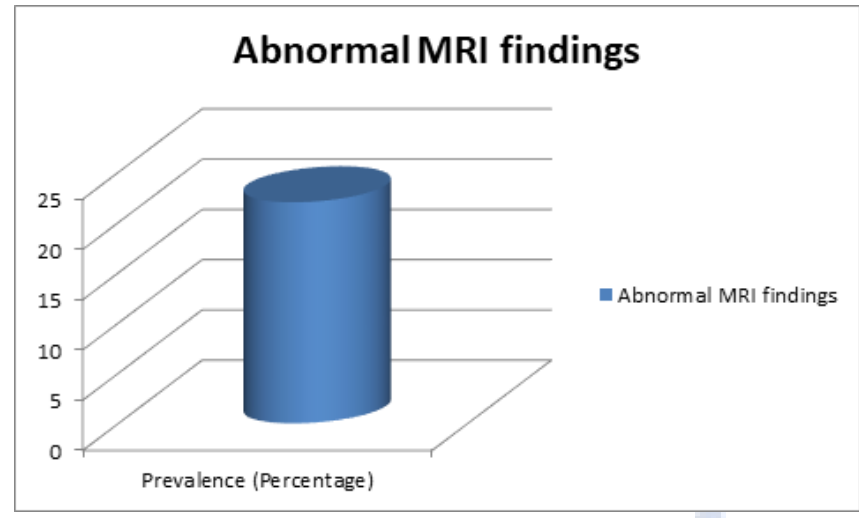

Figure 1: Prevalence of abnormal MRI findings

\section{Discussion}

MRI combines a large strong magnet with radio waves and a computer to provide superbly detailed images of the brain and other parts of the body in multiple planes. MRI is the procedure of choice for evaluating patients with subacute or chronic headaches, a suspected brain tumor, or other spaceoccupying mass and hydrocephalus. Although claustrophobia was a problem for many patients with the early MRI machines, recent developments have made the units much more patient-friendly. ${ }^{[7,8]}$

In the present study, a total of 100 patients with chronic headache were analyzed. Mean age of the patients of the present study was 40.8 years. Majority of the patients (49 percent) belonged to the age group of 30 to 50 years. 31 percent of the patients belonged to the age group of less than 30 years. In a previous study, conducted by Prpic et al, authors determined whether there is significant discrepancy between clinical practice and clinical practice guidelines on the indications for neuroimaging studies. Brain imaging was performed in $164(76.3 \%)$ of 215 children, MRI in 93 $(56.7 \%)$ and CT in $71(43.3 \%)$ children. Indications for brain MRI/CT were as follows: anxiety and/or insistence by the child's family $(71.3 \%)$, presence of associated features suggesting neurologic dysfunction $(13.4 \%)$, age under 5 years $(12.8 \%)$ and abnormal neurologic examination $(2.4 \%)$. The majority of children $(71.4 \%)$ had normal neuroimaging findings. In the rest of imaging studies (28.1\%), MRI/CT revealed different intracerebral/ extracerebral findings not influencing changes in headache management. ${ }^{[9]}$
58 percent of the patients of the present study were males while the remaining 42 percent were females. Abnormal MRI findings were found to be present in 22 percent of the patient population. In another study conducted by Petramfar et al, authors evaluated the ability of neuroimaging to detect potential abnormalities in patients with new onset TTH and normal neurological exam. In a prospective study, 294 cases of new onset TTH with normal neurological exam, that had neuroimaging, were selected. Imaging was evaluated for significant abnormalities. The percentage of abnormal findings in imaging was calculated. 64(21.8\%) patients had MRI. Of them, $21.8 \%$ of MRIs revealed abnormal findings. They concluded that the neuroimaging with current quality does not play an important role in management of patients with new onset TTH and normal neurological exam. ${ }^{[10]}$

Schwedt et al in 2015 did a study functional MRI of migraine. MRI has been used to investigate the mechanisms that lead to migraine sensory hypersensitivities by measuring brain responses to visual, olfactory, and painful cutaneous stimulation, and functional connectivity analyses have investigated the functional organization of specific brain regions and networks responsible for sensory processing. These studies have consistently shown atypical brain responses to sensory stimuli, absence of the normal habituating response between attacks, and atypical functional connectivity of sensory processing regions. Identification of the mechanisms that lead to migraine sensory hypersensitivities and that trigger migraine attacks in response to sensory stimuli might help to better understand neural dysfunction in migraine and provide new targets for migraine prevention, and could provide MRI biomarkers that indicate early responses to preventive therapy. ${ }^{[11]}$

\section{Conclusion}

Under the light of above obtained data, the authors conclude that chronic headache is a common problem affecting significant proportion of patient populating. Significant proportion of patients with chronic headache has associated abnormal MRI findings.

\section{References}

1. Cala LA, Mastaglia FL. Computerized axial tomography findings in a group of patients with migrainous headaches. ProcAustAssoc Neurol. 1976; 13:35-41.

2. Carrera GF, Gerson DE, Schnur J, McNeil BJ. Computed tomography of the brain in patients with headache or temporal lobe epilepsy: findings and cost-effectiveness. J Comput Assist Tomogr. 1977;1(2):200-203.

3. Peters KS. Secondary headache and head pain emergencies. Primary Care: Clinics in Office Practice. 2004;31(2):381-93.

4. Sudlow C, US guidelines on neuroimaging in patients with non-acute headache: a commentary. J NeurolNeurosurg Psychiatry 2002;72(Suppl II):ii16-ii18.

5. Bartleson JD. When and how to investigate the patient with headache. SeminNeurol. 2006;26(2):163-70.

6. Duarte J, Sempere AP, Delgado JA, Naranjo G, Sevillano MD, Claveria LE. Headache of recent onset in adults: a prospective population-based study. ActaNeurol Scand. 1996; 94(1): 67-70.

7. Goadsby PJ. To scan or not to scan in headache. Editorial. BMJ. 2004;329:469-70. 


\section{Patil d Pattl; Prevalence of Alanormal Neuralagical Findings an MRI}

8. Larson EB, Omenn GS, Lewis H. Diagnostic evaluation of headache. Impact of computerized tomography and cost-effectiveness. JAMA. 1980;243(4):359-362.

9. Prpić I, Ahel T, Rotim K, Gajski D, Vukelić P, Sasso A. The use of neuroimaging in the management of chronic headache in children in clinical practice versus clinical practice guidelines. ActaClinicaCroatica. 2014;53(4.):449-54.

10. Petramfar $\mathrm{P}$ and Pishgar S. Neuroimaging in Outpatients with Tension Type Headache. GMJ 2015;4(2):62-6.

11. Schwedt TJ, Chiang CC, Chong CD, Dodick DW. Functional MRI of migraine. The Lancet Neurology. 2015;14(1):81-91.

Copyright: (C) the author(s), publisher. Asian Journal of Medical Radiological Research is an Official Publication of "Society for Health Care $\&$ Research Development". It is an open-access article distributed under the terms of the Creative Commons Attribution Non-Commercial License, which permits unrestricted non-commercial use, distribution, and reproduction in any medium, provided the original work is properly cited.

How to cite this article: Patil PS, Patil NB. Assessment of Prevalence of Abnormal Neurological Findings on MRI in Patients Presenting with Chronic Headache: A Clinical Study.Asian J. Med.Radiol. Res. 2019;7(2):07-09.

DOI: dx.doi.org/10.21276/ajmrr.2019.7.2.3

Source of Support: Nil, Conflict of Interest: None declared.
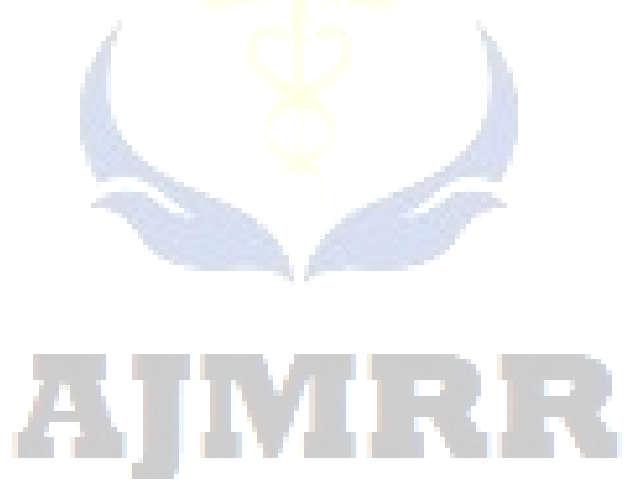